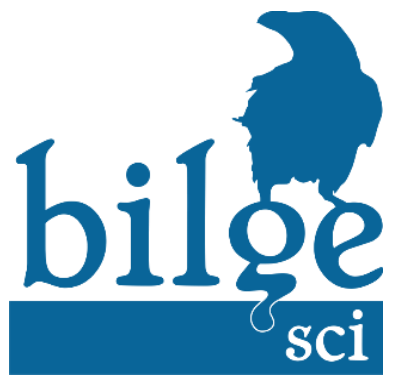

\title{
Preparation and Performance of Electroless Nickel on HVOF (High-Velocity Oxygen Fuel) Sprayed Inconel 625 Nickel Coating for Corrosion Protection Applications
}

\section{Ramazan Haldun Topcu ${ }^{1}$, Harun Mindivan ${ }^{1 *}$}

\begin{abstract}
High Velocity Oxy-Fuel (HVOF) spraying is one of the preferred surface engineering technologies that can offer advantages such as user-friendliness and cost-efficiency in mass production of coatings for various applications. While the main applications of the HVOF process are related to wear, corrosion resistance can be one of the important desired features of the surface engineering process. However, the porosity of HVOF sprayed coatings is usually a problem when coatings are used in corrosion applications. Low carbon steel substrates were High-Velocity Oxygen Fuel (HVOF) sprayed with Inconel 625 and then coated with a thin film of electroless nickel (electroless nickel plating). Characterizations of the coatings were carried out by using X-Ray diffraction analyses (XRD), Optical Microscopy (OM), Scanning Electron Microscope (SEM) and microhardness measurements. Their corrosion behaviours were evaluated by electrochemical polarization measurements in $3.5 \mathrm{wt} . \% \mathrm{NaCl}$ solution. Results showed that sequential application of HVOF spraying and electroless coating processes provided the multi-layered coating consisting of an inner inconel 625 based layer and an outer Ni-P layer. Electroless Ni-P also caused the remarkable increasing in the corrossion resistance as compared to the as-HVOF sprayed state.
\end{abstract}

Keywords: Corrosion, HVOF Spraying, Inconel 625, Electroless Nickel.

\section{Introduction}

The use of thermal sprayed corrosion-resistant coatings to protect an underlying steel substrate has received much interest over the past few years (Johnson et al., 2011). The advantage of this method is the substantial weight and cost reduction compared to using bulk alloys (Hjornhede and Nylund, 2004). A number of thermal spraying methods are available including flame spraying, plasma spraying, arc thermal spraying, and high velocity oxy-fuel (HVOF) spraying (Sidhu et al., 2005). In particular, HVOF is the most extended method to process Inconel 625 coatings (Johnson et al., 2011). However, deposited Inconel 625 coating designed for use in harsh service environments can be damaged because some residual oxides and porosity remain at splat boundaries (Rakhes et al., 2011; Poza et al., 2014). To protect the HVOF sprayed Inconel 625 coating from the above aspects, extensive research is going on in the field of laser cladding onto the Inconel 625 coating by HVOF process (Nemecek et al., 2014). Nevertheless, it was found that the laser coating demonstrated poor corrosion performance because cracking due to rapid melt pool solidification acted as sites for crevice and pitting corrosion (Abioye et al., 2015). Therefore, we additionally carried electroless deposition process to improve the corrosion performance onto the HVOF sprayed Inconel 625 coating to reduce corrosion attack at the coating surface to any open porosity or splat boundaries. According to the available literature, there is no such report on the HVOF sprayed Inconel 625 coating deposited with

${ }^{1}$ Bilecik Şeyh Edebali University, Engineering Faculty, 11210, Bilecik, Turkey

* Corresponding author: *hmindivan@gmail.com
Citation (Atıf): Topcu, R.H., Mindıvan, H. (2018). Preparation and Performance of Electroless Nickel on HVOF (High-Velocity Oxygen Fuel) Sprayed Inconel 625 Nickel Coating for Corrosion Protection Applications. Bilge International Journal of Science and Technology 
electroless Ni-P. In the present study, the HVOF-sprayed Inconel 625 coating has been subjected to Ni-P coating and then its structural characterization and corrosion properties have been evaluated.

\section{Material and Method}

Commercially available spheroidal, gas atomized powder (Diamalloy-1005) manufactured by Sulzermetco company with a nominal particle size range of -45 to $+11 \mu \mathrm{m}$ was used for this study. These particles are similar to Inconel 625 properties and composition (Table 1). It is used in corrosive and erosive applications like seawater environments. Inconel 625 was deposited onto rectangular low carbon steel substrates with dimensions of $100 \mathrm{~mm} \times 50 \mathrm{~mm} \times 4 \mathrm{~mm}$ (length $\mathrm{x}$ width $\times$ thickness). The oxide film on the substrate was removed with sandblasting followed by cleaning acetone to eliminate any residuals prior to HVOF spray process.

Table 1. Chemical Composition of Diamalloy-1005 Powder.

\begin{tabular}{|c|c|c|c|c|c|}
\hline Powder & \multicolumn{5}{|c|}{ Chemical Composition (wt. \%) } \\
\cline { 2 - 6 } Material & $\mathrm{Ni}$ & $\mathrm{Cr}$ & $\mathrm{Mo}$ & $\mathrm{Fe}$ & $\mathrm{Co}$ \\
\hline Inconel 625 & 66.5 & 21.5 & 8.5 & 3 & 0.5 \\
\hline
\end{tabular}

Before electroless Ni-P coating, the surfaces of the HVOF sprayed Inconel 625 coating were ground using 1200 grit $\mathrm{SiC}$ paper and mechanically polished with a fine grade $\mathrm{Al}_{2} \mathrm{O}_{3}$ paste to achieve a certain surface uniformity. Finally, the surfaces were thoroughly degreased with acetone, ultrasonically cleaned and etched in a 30 vol. $\% \mathrm{HCl}$ solution for $1 \mathrm{~min}$. The commercial Ni-P electroless solution (Durni-Coat DNC 520-9) containing $5 \mathrm{~g} / \mathrm{L}$ nickel, $40 \mathrm{~g} / \mathrm{L} \mathrm{NaH} \mathrm{PO}_{2}$ and suitable amounts of additive and stabilizer were used. The stirring rate of plating bath was about $250 \mathrm{r} / \mathrm{min}$, using a magnetic stirrer and a polytetrafluoroethylene (PTFE) coated magnet with $2 \mathrm{~cm}$ length and $5 \mathrm{~mm}$ in diameter. The deposition was carried out in a $250 \mathrm{ml}$ thermostated double wall beaker at $90{ }^{\circ} \mathrm{C}$ and $\mathrm{pH} 4.6$ for $1 \mathrm{~h}$ to achieve a thickness of $11.5 \mu \mathrm{m}$.

Characteristics of the HVOF sprayed Inconel 625 and Ni-P treated coatings were investigated by microscopic examinations, X-ray diffraction (XRD) analyses, microhardness measurements and corrosion tests. The cross-sectional microstructure of the coatings was inspected with an Optical Microscopy (OM) and a Scanning Electron Microscope (SEM) equipped with an Energy Dispersive Spectroscopy (EDS). The crosssectional microhardness measurements were carried out using a Vickers microhardness tester (Shimadzu) with a load $50 \mathrm{~g}$ and a dwell time of $10 \mathrm{~s}$.

The electrochemical corrosion tests of the coatings were performed utilizing a typical three electrode potentiodynamic polarization test unit in the corroding media of aerated solution of $3.5 \mathrm{wt}$. $\% \mathrm{NaCl}$ at room temperature. Before potentiodynamic polarization measurements, an initial delay of $30 \mathrm{~min}$. was employed in order to measure the open circuit potential between working and reference electrodes. Potentiodynamic polarization curves were generated by sweeping the potential from cathodic to anodic direction at a scan rate of $1 \mathrm{mVs}^{-1}$, starting from -0.8 up to $-0.2 \mathrm{~V}$. The corrosion potential $\left(\mathrm{E}_{\text {corr }}\right)$ and corrosion current density $\left(\mathrm{i}_{\text {corr }}\right)$ were determined using the Tafel extrapolation method. Finally, the surface images of the corroded coatings were examined using an OM in order to determine the morphology of the developed corrosion.

\section{Results and Discussion}

Figure 1 shows OM images of the cross section of the HVOF sprayed Inconel 625 coating on low carbon steel substrate. The characteristic structure of an as-sprayed Inconel 625 coating with thickness of approximately $350 \mu \mathrm{m}$, formed by incremental deposition of powder particles which deform on impact is shown in Fig. 1 (a). Three discernable levels of contrast, white, black, and gray, were seen in the microstructure. The black regions mostly located along the interface of the splats were identified as pores (Fig. $1 \mathrm{~b}$, as shown by the white arrows). EDS characterization was conducted to determine the composition of the white and gray areas. According to the EDS results, white regions represented the base material (Inconel 625) and the gray region represented oxide. 
Figure 2 depicts surface morphology and cross-sectional micrograph of the Ni-P deposit. Because of the low amount of nodules on the Ni-P deposit (Fig. 2 a), it seems that the Ni-P coated surface had a low roughness value $\mathrm{Ra}=0.16 \pm 0.01 \mu \mathrm{m}$. Using the EDS analysis, it was determined that the Ni-P deposit contains $13 \mathrm{wt}$. $\%$ phosphorous and $87 \mathrm{wt}$ \% nickel. The coating with thickness of approximately $11.5 \mu \mathrm{m}$ was rather compact without macro-defects such as porosity and showed a relatively good adherence to the HVOF sprayed Inconel 625 coating (Fig. 2 b). After electroless Ni-P coating, a 1.16 fold increase in hardness (415 $\left.\mathrm{HV}_{0.05}\right)$ was achieved compared to the HVOF sprayed Inconel 625 coating not subjected to electroless deposition $\left(355 \mathrm{HV}_{0.05}\right)$.
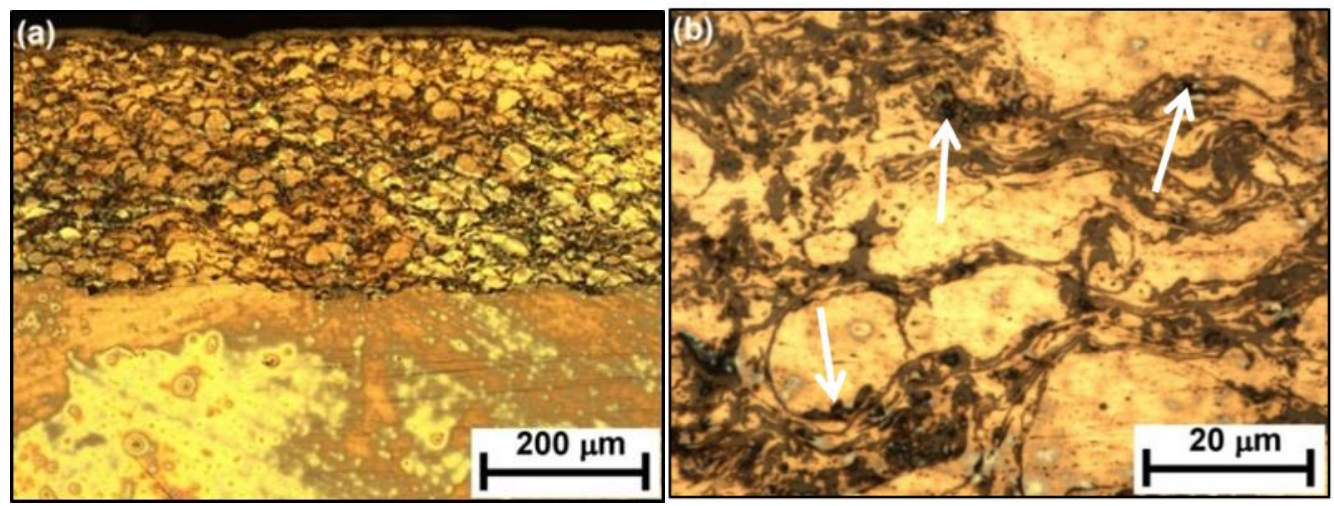

Figure 1. Cross sectional observations of HVOF sprayed Inconel 625 coating (a) low-magnification and (b) high-magnification.

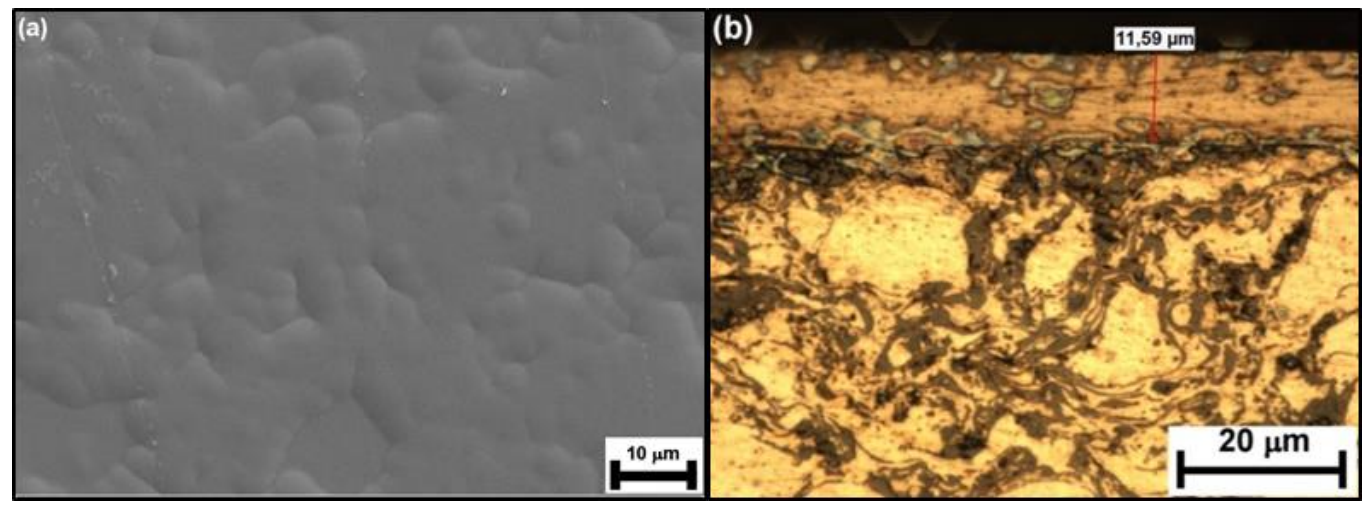

Figure 2. (a) Surface morphology and (b) cross-section image of the Ni-P deposit.

The XRD patterns of the examined coatings are presented in Figure 3. The HVOF sprayed Inconel 625 coating presented $\mathrm{FeNi}, \mathrm{Ni}, \mathrm{Fe}_{2} \mathrm{O}_{3}$ and $\mathrm{NiO}$ phases. After electroless plating on the HVOF sprayed Inconel 625 coating, Ni-P fully coated on the surface as shown in XRD pattern of the Ni-P deposit. XRD pattern of the Ni-P deposit exhibited a single broad peak indicative of the amorphous nature of the coating along with the presence of a small crystallite in the coating microstructure (Fig. 3). 


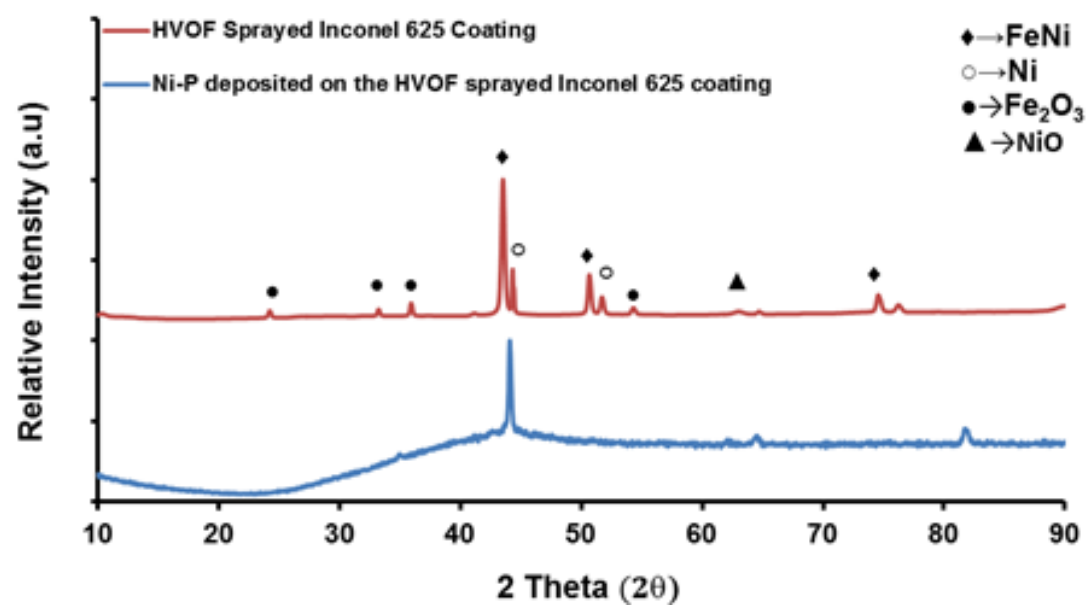

Figure 3. XRD patterns of the examined coatings.

Representative potentiodynamic polarization curves obtained for all the coatings are displayed in Fig. 4. The corresponding electrochemical corrosion parameters are shown in Table 2. As can be seen from Fig. 4, the equilibrium corrosion potential $\left(\mathrm{E}_{\text {corr }}\right)$ of the HVOF sprayed Inconel 625 coating was $-575 \mathrm{mV}$, and the corrosion current density ( $\mathrm{I}_{\text {corr }}$ ) was $3.38 \times 10^{-6} \mathrm{Acm}^{-2}$. The corrosion potential and corrosion current density of the Ni-P deposit were changed. The Ni-P deposit's $\mathrm{E}_{\text {corr }}$ was $-487 \mathrm{mV}$, which was positively shifted $88 \mathrm{mV}$. Besides, the $\mathrm{I}_{\text {corr }}$ was $2.04 \times 10^{-6} \mathrm{Acm}^{-2}$ which was reduced $1.34 \times 10^{-6} \mathrm{Acm}^{-2}$. $\mathrm{E}_{\text {corr }}$ indicates the tendency of the sample to corrode. The more negative the value is, the more likely it is that electrochemical corrosion will occur. $\mathrm{I}_{\text {corr }}$ indicates how quickly the sample corrodes once it has been corroded. Therefore, from the analysis results shown in Fig. 4 and Table 2, the improved corrosion resistance for Ni-P deposit in comparison with the HVOF sprayed Inconel 625 coating is ascribed to dense and porosity free coating as revealed from microhardness evaluation.

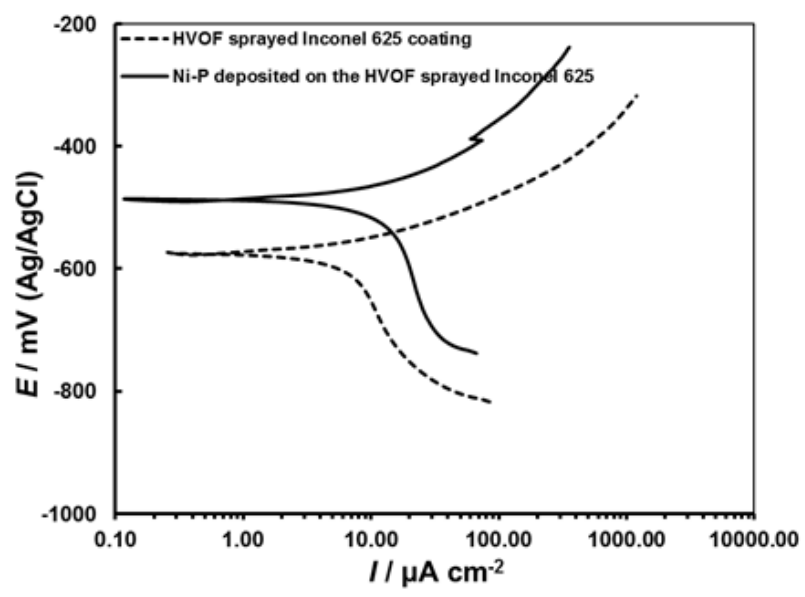

Figure 4. Potentiodynamic polarisation curves for the examined coatings in a $3.5 \mathrm{wt} . \% \mathrm{NaCl}$ solution. 
Table 2. Corrosion potential and corrosion current density values obtained from the polarization curves.

\begin{tabular}{ccc}
\hline Type of coating & $\begin{array}{c}\mathbf{E}_{\text {corr, }}, \\
(\mathbf{m V})\end{array}$ & $\begin{array}{c}\mathbf{I}_{\mathbf{c o r r}}, \mathbf{A c m}^{-2}, \\
(\mathbf{x 1 0})\end{array}$ \\
\hline HVOF sprayed Inconel 625 coating & -575 & 3.38 \\
& & \\
\hline Ni-P treated coating & -487 & 2.04 \\
\hline
\end{tabular}

Figure 5 shows the corroded surfaces of the coatings. After polarization testing in $3.5 \mathrm{wt} \% \mathrm{NaCl}$ solution, the HVOF sprayed Inconel 625 coating showed an isolated corrosion pits on the surface. However, a lower Inconel 625 layer obtained by HVOF thermal spray process with an upper electroless Ni-P deposit was quite smooth and did not show sign of corrosion. The results suggest that the Ni-P deposit is more protective in nature than HVOF sprayed Inconel 625 coating. In agreement with these results, this significant enhancement in the corrosion resistance of amorphous electroless Ni-P (with high P content) coating is due to the absence of grain boundaries and the possible formation of a protective layer of nickel oxide and phosphorus compound (Yan et al., 2015).
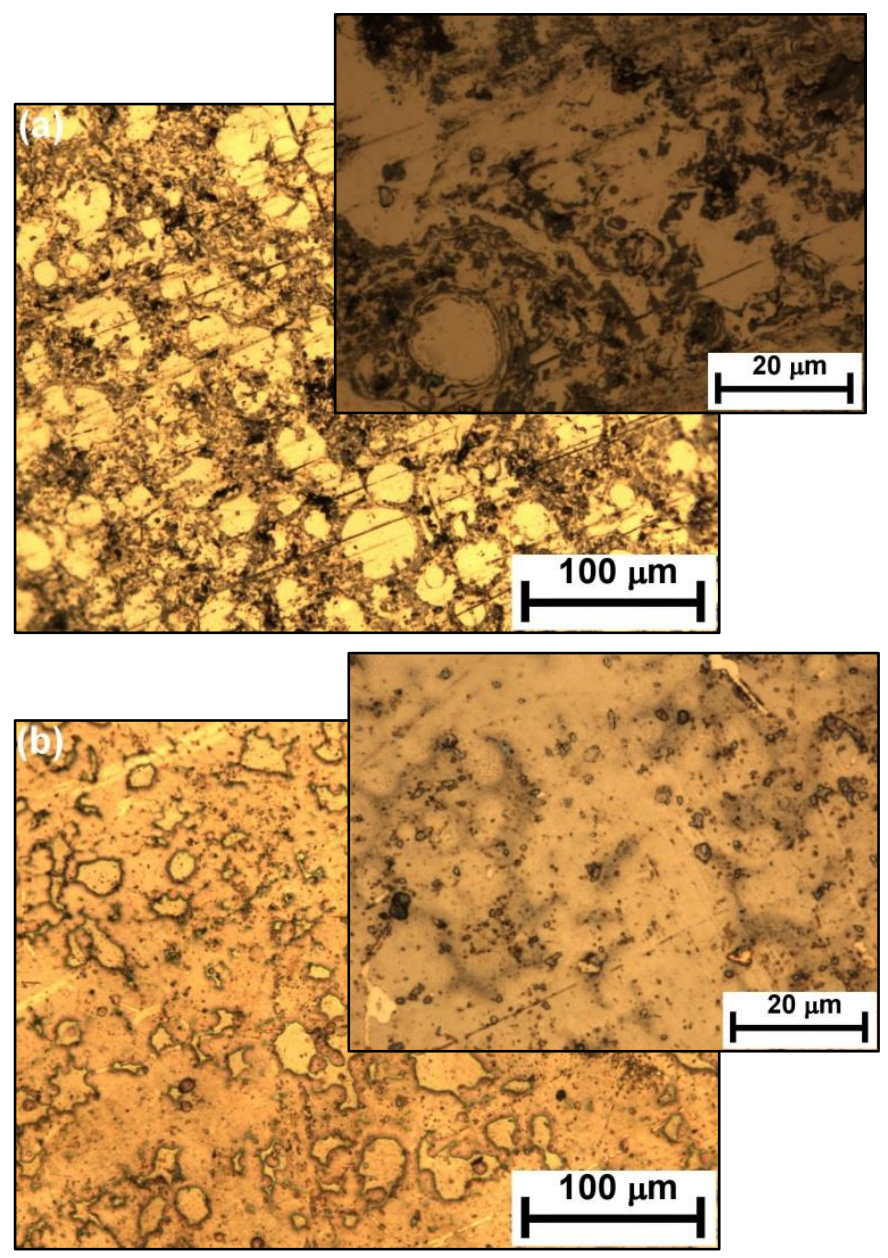

Figure 5. OM images of the (a) HVOF sprayed Inconel 625 coating and (b) Ni-P treated coating after polarization test. 


\section{Conclusions}

HVOF thermal spray layer (Inconel 625) was coated with electroless Ni-P. The coatings were characterised by microstructure analysis, microhardness measurements and corrosion tests, and the most relevant conclusions can be summarised as follows:

-HVOF sprayed Inconel 625 coating followed by electroless Ni-P showed higher hardness and denser structure without porosity when compared to the coating without Ni-P deposit.

-The corrosion resistance of Inconel 625 coating obtained by HVOF thermal spray technology has been enhanced by adding an upper layer of a Ni-P deposit.

\section{References}

Abioye, T.E., McCartney, D.G., Clare, A.T. (2015). Laser cladding of Inconel 625 wire for corrosion protection. Journal of Materials Processing Technology, 217, 232-240.

Hjornhede, A., Nylund, A. (2004). Adhesion testing of thermally sprayed and laser deposited coatings. Surface and Coatings Technology 184, 208-218.

Johnson, L., Niaz, A., Boatwright, A., Voisey, K.T., Walsh, D.A. (2011). Scanning electrochemical microscopy at thermal sprayed anti-corrosion coatings: Effect of thermal spraying on heterogeneous electron transfer kinetics. Journal of Electroanalytical Chemistry, 657, 46-53.

Nemecek, S., Fidler, L., Fišerova, P. (2014). Corrosion resistance of laser clads of Inconel 625 and Metco 41C. Physics Procedia, 56, $294-300$.

Poza, P., Múnez, C.J., Garrido-Maneiro, M.A., Vezzù, S., Rech, S., Trentin, A. (2014). Mechanical properties of Inconel 625 cold-sprayed coatings after laser remelting. Depth sensing indentation analysis. Surface \& Coatings Technology, 243, 51-57.

Rakhes, M., Koroleva, E., and Liu, Z. (2011). Improvement of corrosion performance of HVOF MMC coatings by laser surface treatment. Surface Engineering, 27 (10), 729-733.

Sidhu, T. S., Prakash, S., and Agrawal, R. D. (2005). Studies on the properties of high-velocity oxy-fuel thermal spray coatings for higher temperature applications. Materials Science, 41(6), 805-823.

Yan, D., G. Yu, B. Hu, J. Zhang, Z. Song, X. Zhang. (2015). An innovative procedure of electroless nickel plating in fluoride-free bath used for AZ91D magnesium alloy. Journal of Alloys and Compounds $653,271-278$. 